(2) Open Access Full Text Article

ORIGINAL RESEARCH

\title{
Knowledge of Risk Factors and Warning Signs of Stroke Among Patients with Heart Disease at Tikur Anbessa Specialized Hospital
}

This article was published in the following Dove Press journal: Open Access Emergency Medicine

\author{
Abdata Workina (1D \\ Sofia Kebede ${ }^{2}$ \\ Chala Fekadu ${ }^{3}$ \\ Andualem Wubetie Snr ${ }^{2}$ \\ 'School of Nursing, Jimma University, \\ Jimma, Oromia, Ethiopia; ${ }^{2}$ Department of \\ Emergency Medicine, Addis Ababa \\ University, Addis Ababa, Ethiopia; \\ ${ }^{3}$ Department of Internal Medicine, Addis \\ Ababa University, Addis Ababa, Ethiopia
}

Correspondence: Abdata Workina School of Nursing, Jimma University, P.O. Box-378, Jimma, Oromia Region, Ethiopia

Tel +251923643857

Email abdeta.15@gmail.com
Background: Stroke is a leading cause of mortality and disability worldwide and the economic costs of treatment and post-stroke care are extensive. The inability to identify stroke warning signs accurately is an important cause of delay in seeking medical attention, leading to potential ineligibility for acute intervention and which leads to secondary complications.

Purpose: To identify cardiac patients' knowledge of stroke risk factors and warning signs. Patients and Methods: The institutional based cross-sectional study design was employed. Participants were selected using systematic random sampling. Close-ended questionnaires were pre-tested and validated for consistency before data collection. Then after data collection, data were checked and entered into Epi-data 4.6. Finally, the cleaned data were exported to SPSS version 25 for analysis. Statistical analysis using binary logistic regression was done and Predictors with a p-value of $<0.05$ were considered statistically significant.

Results: A total of 227 patients were included in the study, of which 140 (61.7\%) of them identified physical inactivity, followed by hypertension126 (55.5\%) as stroke risk factor while $15.4 \%$ of them did not know any risk factor of stroke. Amongst the study participants, $45.81 \%$ of them had adequate knowledge of stroke risk factors. Regarding stroke warning signs the most identified sign was sudden unilateral weakness $142(62.6 \%)$ while 46 (20.26\%) of them did not know at least one warning sign of a stroke. Based on multivariable logistic regression analysis, higher education level AOR 3.05 (95\% CI 1.62-5.74) and Urban residence area AOR 2.07 (95\% CI 1.05-4.1) were significantly associated with knowledge of stroke risk factors with $\mathrm{p}$-value $<0.05$.

Conclusion: Study participants had inadequate knowledge of stroke risk factors and warning signs. Educational status and information about stroke are significantly associated with adequate knowledge of stroke risk factors, raising stroke awareness is the mainstay to reduce stroke burden.

Keywords: knowledge, risk factors, stroke, a warning sign

\section{Introduction}

Stroke is a leading cause of mortality and disability worldwide and the economic costs of treatment and post-stroke care are substantial. ${ }^{1}$ The inability to identify stroke warning signs accurately is an important cause of delay in seeking medical attention, leading to potential ineligibility for prompt intervention. ${ }^{2}$ Prevention of main modifiable risk factors of cardiovascular diseases (CVD) such as hypertension, diabetes mellitus, physical inactivity, smoking, and obesity through effective prevention strategies consequently reduces disability and mortality occurs due to stroke. ${ }^{3-5}$ 
World stroke association practices warning signs of stroke using the acronym FAST (face, arm, speech, time) message campaign, to explain knowing the signs of stroke and getting treatment quickly saves lives and improves recovery even though the stroke burden is increasing globally. $3,4,6,7$

A good functional outcome from a stroke begins when the public recognizes stroke warning signs. ${ }^{8,9}$ However, the public's knowledge of stroke warning signs remains poor. ${ }^{6,10}$ Evidence from studies in developed and developing countries shows that respondents' recognition of any of the established stroke risk factors or warning signs is generally less than $50 \% .{ }^{11-13}$ A pre-hospital delay is shortened through advanced notification of stroke warning signs and increases the use of the intravenous recombinant tissue-type plasminogen activator. ${ }^{1,3,11}$

The overall stroke burden has increased globally, due to poor community knowledge of stroke risk factors and its warning signs. ${ }^{14-16}$ Necessary intervention should be carried out to decrease stroke other communicable disease burdens, otherwise, the total death from it is anticipated to increase further $17 \%$ over the next first decade. ${ }^{12,13}$

The 2014 WHO report states that stroke accounted for $4.71 \%$ of total deaths and the leading cause of disability (6458 age-standardized DALYs per 100,000) in Ethiopia. ${ }^{17,18}$ This is due to delayed presentation and the increasing burden of stroke risk factors. ${ }^{19-22}$

Given the already huge and fast-increasing burden of stroke which threatens worldwide sustainability, governments of all countries should develop and implement an emergency action plan addressing the primary prevention of NCDs, to tackle unhealthy behaviors that increase the risk of stroke. ${ }^{4,23-25}$ So, the main objective of this study is to show the gap between unhealthy behaviors that increase the occurrence of stroke and reduce the pre-hospital delay that occurs due to a lack of awareness on recognition of stroke warning sign and its associated factors.

\section{Patients and Methods}

\section{Study Design and Setting}

An institutional-based cross-sectional study design was conducted at Tikur Anbessa specialized hospital from March 15 to April 25, 2020. Tikur Anbessa specialized hospital is located in the capital city of Ethiopia. It is the largest teaching hospital in the country, which provides health care services to over 700,000 patients per year and serves as a training and teaching center for health programs. ${ }^{25,26}$

\section{Study Population}

Patients with heart disease who visit Tikur Anbessa specialized hospital cardiac clinic for follow-up during the study period.

\section{Eligibility Criteria}

Cardiac patients aged $\geq 18$ years who visit TASH outpatient cardiac clinic were included in the study, while critically ill and psychiatric patients were excluded.

\section{Sample Size Determination and Sampling Procedure}

The required sample size was determined using the single population proportion formula with the assumption of $95 \%$ confidence level, $5 \%$ margin of error, and $18.3 \%$ proportion of hypertensive patients who have good knowledge of stroke risk factors. ${ }^{13}$ The initial sample size $(\mathrm{ni})=(\mathrm{Z} \alpha / 2) 2 \mathrm{p}$ $(1-\mathrm{p}) / \mathrm{d} 2=230$ was adjusted using a correction formula for a total of 2380 outpatient cardiac patients who were on follow-up were eligible for the study based on inclusion criteria from the follow-up chart was taken. Finally, a total of 231 cardiac patients were targeted for the study after the addition of a $10 \%$ non-response rate. Patients' record order which was listed in follow-up appointment was used as a sampling frame, Study participant was selected by systematic random sampling technique a using list of record orders in the follow-up chart with sampling interval (k) $=\mathrm{N} / \mathrm{nf} ; 2380 / 231=10$; then, in every 10 intervals, participants selected until reaching the total sample size and the first participant was selected by lottery method.

\section{Data Collection Tool and Procedure}

Close-ended standard stroke awareness questionnaires were adapted which contain socio-demographic characteristics, stroke risk factors, and stroke warning signs used in the previous literature that were used., ${ }^{9,13,27,28}$ The patients' knowledge of stroke risk factors and warning signs were categorized based on the number of correct answers of stroke warning signs and warning signs, respectively. Participants who selected the yes option from each listed risk factors and warning signs of stroke were considered correct. Therefore, participants who identified $>3$ risk factors or warning signs of stroke were categorized as having good knowledge of stroke risk factors or 
its warning signs, respectively. ${ }^{29,30}$ Face to face interview technique was conducted by trained four BSc nurses.

\section{Data Quality Assurance}

The questionnaire was pretested on $5 \%$ of the sample size on patients with heart disease who are on follow-up at Saint Paul hospital. During the pre-test, the questionnaire was assessed for its understandability, and reliability statistics were computed with Cronbach's alpha of 0.87 . Questionnaires were translated to Amharic and Afan Oromo languages by language experts then back to English during data analysis. The training was given for data collectors and the supervisor provided on-site close supervision during data collection.

\section{Data Processing and Analysis}

Data were checked for completeness and entered into Epidata entry client version 4.6. Then, it was exported to and analyzed using SPSS version 25.0. Descriptive statistics were computed to summarize categorical variables of patients' characteristics. The statistical analysis using binary logistic regression was done to determine candidate variables for multivariable logistic regression at $\mathrm{p}$-value $<0.25$. Then, variables having $\mathrm{p}$-value $<0.05$ at $95 \% \mathrm{CI}$ in multivariable logistic regression were considered statistically significant.

\section{Ethical Consideration}

The letter of permission was approved by the Addis Ababa University College of health science department of emergency medicine ethical review committee with Ref No: EM/SM/350/2012 and was given to Tikur Anbessa specialized hospital administrator and this study was conducted in accordance with Helsinki declaration. Written informed consent was taken from each participant. Data collectors explained the objectives and their right to refuse and discontinue the data collection.

\section{Results}

A total of 227 participants were included in the study giving a response rate of $98.3 \%$. The mean age of respondents was $46.2 \pm \pm 17.9$. Regarding the sex of participants more than half $132(58.1 \%)$ were females, and around two-thirds $(69.2 \%)$ of patients were married. Concerning educational status, $64(28.2 \%)$ of them learned up to elementary school. Most of the participants' residence area was urban which accounts for 154 (67.8\%) (Table 1).

\section{Knowledge of Stroke Risk Factors}

The most identified stroke risk factor by respondents was physical inactivity140 (61.7\%) of them followed by hypertension 126 (55.5\%), whereas only less than half (42.7\%) of study participants identified diabetes mellitus as a risk factor of stroke (Table 2). Among the study participants around $15.4 \%$ of them did not know any risk factor of stroke, while $16.3 \%$ of them identified five risk factors of stroke followed by $15.9 \%$ of the respondents identified all (6) listed risk factors (Figure 1). Among the study participants, less than half $(45.8 \%)$ of them had adequate knowledge of stroke risk factors.

\section{Knowledge of Stroke Warning Signs}

A majority, 142 (62.6\%) of the study participants identified sudden unilateral numbness/weakness of the face, arm, or leg, followed by sudden trouble with walking, loss of balance $137(60.4 \%)$ as the warning signs of a stroke, whereas sudden trouble with seeing in one or both eyes is least,93 (41.0\%), known warning signs of stroke among study respondents (Table 3 ). Among the study participants, $46(20.3 \%)$ of them did not know at least one warning sign of stroke, while $49(21.1 \%)$ of the respondents recall 5 warning signs of a stroke (Figure 2). Only Less than half $(42.7 \%)$ of study respondents had adequate knowledge about stroke warning signs.

\section{Factors Associated with Stroke Risk Factors and Warning Signs}

In the bivariate logistic regression, age, educational level, occupation, residence area, hearing about stroke, and knowing somebody with stroke were found to have a significant association with knowledge of stroke risk factors and warning signs (Table 4).

In the multivariable logistic regression educational level, residence area, and knowing somebody with stroke were significantly associated with knowledge of stroke risk factors and warning signs having a P-value of $<0.05$. The odds of having adequate knowledge of stroke risk factors among those who had a higher educational level was 3.05 times (AOR 3.05; 95\% CI 1.62-5.74, $\mathrm{P}=0.005$ ) than participants who had educated less than high school. Urban residence area was 2.07 times (AOR 2.07; 95\% CI 1.05-4.1, $\mathrm{P}=0.036$ ) more likely to have adequate knowledge of stroke risk factors than participants who live in the rural area. Furthermore, knowing somebody with stroke was 2.67 times (AOR 2.67; 95\% CI $1.29-5.55, \mathrm{P}=0.008)$ more likely to have adequate 
Table I Socio-Demographic Characteristics of Patients with Heart Disease Who are on Follow-Up at Tikur Anbessa Hospital, $2020(n=227)$

\begin{tabular}{|c|c|c|c|c|}
\hline \multicolumn{3}{|l|}{ Variables } & \multirow[t]{2}{*}{ Frequency } & \multirow[t]{2}{*}{ Percent } \\
\hline \multirow[t]{4}{*}{ Age } & $\begin{array}{l}\text { Mean } \pm S D \text { in } \\
\text { years }\end{array}$ & $46.2 \pm 17.9$ & & \\
\hline & \multicolumn{2}{|l|}{$18-44$} & 104 & 45.8 \\
\hline & \multicolumn{2}{|l|}{$45-64$} & 79 & 34.8 \\
\hline & \multicolumn{2}{|l|}{$\geq 65$} & 44 & 19.4 \\
\hline \multirow{8}{*}{$\begin{array}{l}\text { Clinical profile of } \\
\text { patients }\end{array}$} & \multicolumn{2}{|c|}{ Valvular heart disease } & 26 & 11.5 \\
\hline & \multicolumn{2}{|c|}{ Heart failure } & 19 & 8.4 \\
\hline & \multicolumn{2}{|c|}{ Hypertension } & 73 & 32.1 \\
\hline & \multicolumn{2}{|l|}{ Dyslipidemia } & 14 & 6.2 \\
\hline & \multicolumn{2}{|c|}{ Heart rhythm disorder } & II & 4.8 \\
\hline & \multicolumn{2}{|c|}{ Congenital heart defects } & 23 & 10.1 \\
\hline & \multirow{2}{*}{\multicolumn{2}{|c|}{ Heart infections }} & 24 & 10.6 \\
\hline & & & 37 & 16.3 \\
\hline \multirow[t]{2}{*}{ Sex } & \multicolumn{2}{|l|}{ Male } & 95 & 41.9 \\
\hline & \multicolumn{2}{|l|}{ Female } & 132 & 58.1 \\
\hline \multirow[t]{4}{*}{ Marital status } & \multicolumn{2}{|l|}{ Married } & 157 & 69.2 \\
\hline & \multicolumn{2}{|l|}{ Single } & 43 & 18.9 \\
\hline & \multicolumn{2}{|l|}{ Divorced } & 16 & 7.0 \\
\hline & \multicolumn{2}{|l|}{ Widowed } & II & 4.8 \\
\hline \multirow[t]{4}{*}{ Educational status } & \multirow{4}{*}{\multicolumn{2}{|c|}{$\begin{array}{l}\text { Illiterate } \\
\text { Elementary } \\
\text { High school/preparatory } \\
\text { College and above }\end{array}$}} & 53 & 23.3 \\
\hline & & & 64 & 28.2 \\
\hline & & & 62 & 27.3 \\
\hline & & & 48 & 21.1 \\
\hline \multirow[t]{6}{*}{ Occupation } & \multicolumn{2}{|l|}{ Farmer } & 34 & 15.0 \\
\hline & \multicolumn{2}{|l|}{ Merchant } & 71 & 31.3 \\
\hline & \multicolumn{2}{|c|}{ Government employee } & 32 & 14.1 \\
\hline & Housewife & & 54 & 23.8 \\
\hline & Student & & 17 & 7.5 \\
\hline & Other* & & 19 & \\
\hline Monthly income & $\leq 5000$ & & 27 & 11.9 \\
\hline in ETB & $<5000$ & & 200 & 88.1 \\
\hline Residence area & Urban & & 154 & 67.8 \\
\hline & Rural & & 73 & 32.2 \\
\hline
\end{tabular}

Note: *Daily laborer, jobless, pensioner.

knowledge of stroke risk factors than others who do not know somebody with stroke. Concerning knowledge of warning signs, the odds of having adequate knowledge of stroke warning signs were 2.95 times (AOR 2.95; 95\% CI $1.28-6.83, \mathrm{P}=0.107)$ in participants who had higher educational level than those who had educational level less than high school, besides to this know somebody with stroke was 10.85 times (AOR 10.85; 95\% CI 4.38-26.90, $\mathrm{P}=0.000$ ) more likely to have adequate knowledge of stroke warning signs than others who not know somebody with stroke (Table 5).
Table 2 Risk Factors of Stroke Identified by Patients with Heart Disease Who are on Follow-Up at Tikur Anbessa Hospital, 2020 $(n=227)$

\begin{tabular}{|l|l|l|l|}
\hline \multicolumn{2}{|l|}{ Variables } & Frequency & Percent \\
\hline Hypertension & No & 126 & 55.5 \\
& I do not know & 63 & 16.7 \\
& Yes & 123 & 27.8 \\
\hline Obesity & No & 52 & 54.2 \\
& I do not know & 52 & 22.9 \\
\hline \multirow{2}{*}{ Excessive alcohol intake } & Yes & 122 & 22.9 \\
& No & 54 & 53.7 \\
& I do not know & 5 I & 23.8 \\
\hline \multirow{2}{*}{ Diabetes mellitus } & Yes & 97 & 42.5 \\
& No & 49 & 21.6 \\
& I do not know & 8 I & 35.7 \\
\hline Physical inactivity & Yes & 140 & 61.7 \\
& No & 30 & 13.2 \\
& I do not know & 57 & 25.1 \\
\hline Smoking & Yes & 108 & 47.6 \\
& No & 49 & 21.6 \\
& I do not know & 70 & 30.8 \\
\hline
\end{tabular}

\section{Discussion}

To tackle global invisible socio-economic burdens of stroke; prevention is the mainstay both in low- and highincome countries, so this study aims to identify participants' awareness of stroke risk factors and its warning signs.

Most study participants identified physical inactivity $140(61.7 \%)$ of them as a risk factor of stroke followed by hypertension $126(55.5 \%)$, while the least known risk factor of stroke was diabetes mellitus 97 (42.7\%). This study finding is relatively consistent with a study conducted in Pakistan that shows a majority (63.5\%) of patients identified hypertension as a risk factor for stroke. ${ }^{29}$ Besides this study conducted in Lebanon reveals $188(48.2 \%)$ of them had identified hypertension as stroke risk factors. ${ }^{31}$ And also, relatively consistent with a study conducted in Nigeria that reveals the most recalled stroke risk factors were hypertension 71 (45.4\%) and diabetes 72 $(42.2 \%){ }^{27}$ This might be due to the study participants with an identical study design. This study finding was, in contrast, to a study conducted in Spain that shows that $22.68 \%$ of the study participants identified hypertension as a stroke risk factor. ${ }^{32}$ This inconsistency might be due to the study 


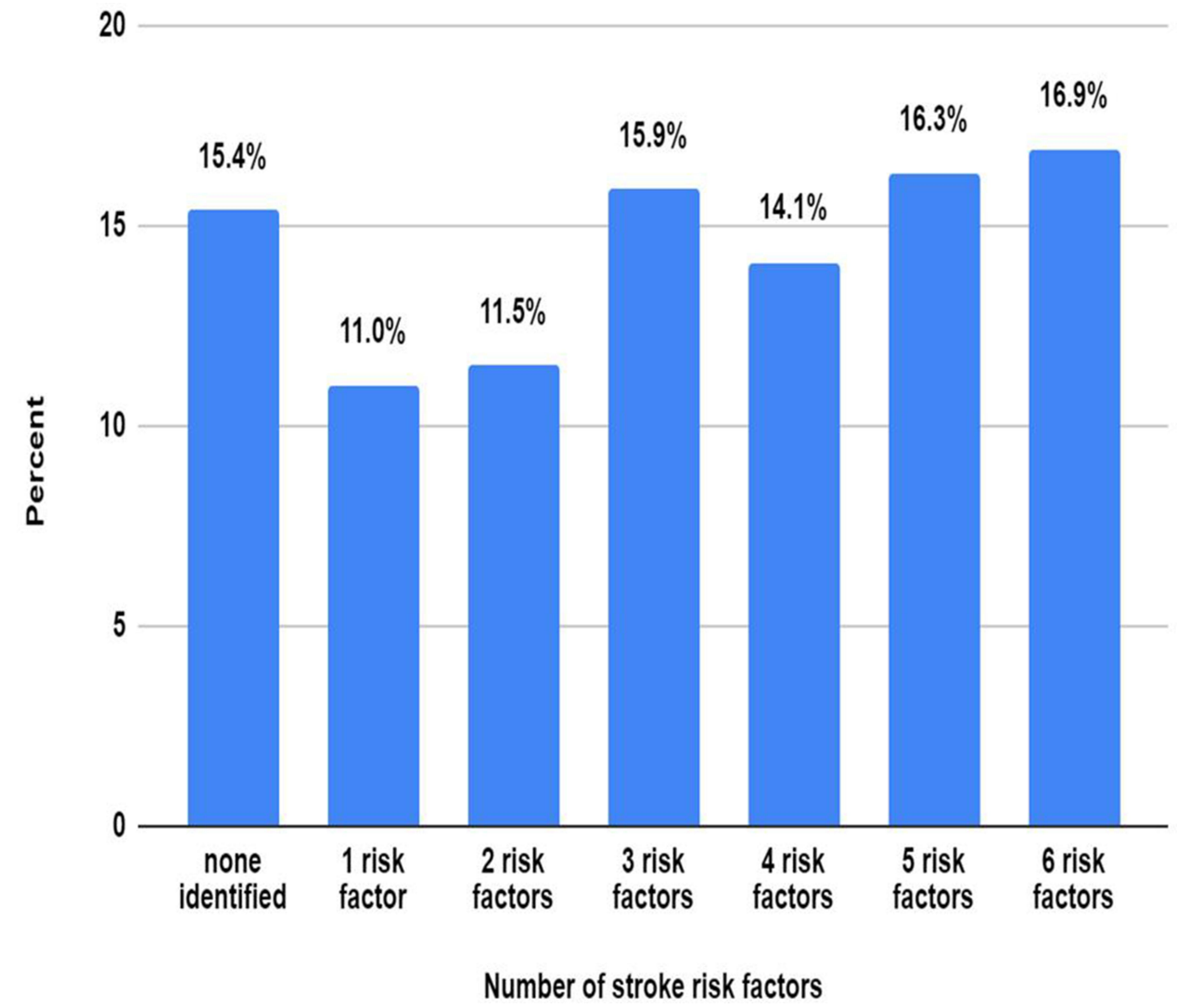

Figure I Number of stroke risk factors identified by patients with heart disease who were on follow-up at TASH, 2020.

being conducted on admitted stroke patients, stroke may affect the intellectual ability of the study participants. Our findings were also inconsistent with studies conducted in Korea and the USA. ${ }^{30,33}$ This might be due to the health care information access gap and socioeconomic status difference between low- and high-income countries. However, this study finding was higher than the study finding conducted in Ethiopia. ${ }^{13}$ This gap might be due to increasing health care awareness and a difference in the study site and residency of participants within the country. Among the study participants, around $15.4 \%$ of them did not know any risk factor of stroke, while $15.9 \%$ of them identified all listed risk factors. Besides this less than half $(45.8 \%)$ of them had adequate knowledge of stroke risk factors. This study finding is relatively consistent with the study conducted in Thailand that shows a quarter of patients $(25 \%)$ could not name any risk factors for stroke. ${ }^{28}$ This study was also relatively similar to a study conducted at Benin that reveals $82(56.9 \%)$ of participants had good knowledge of stroke risk factors. ${ }^{27}$ The similarity might be due to studies that were conducted on similar types of study participants. In contrast to these studies, studies conducted in the USA and Korea show participants knowledge of correct stroke risk factors $>3$ accounts 117 $(71.8 \%)$ and more than $60 \%$ of the participants recognized over-all the risk factors, respectively. ${ }^{30,33}$ This shows a higher number of study participants had adequate knowledge of stroke risk factors. The possible justification for it was due to rising health care awareness in such study areas, the difference in socioeconomic status, and study participants' selection method.

Regarding knowledge of stroke warnings sign, sudden unilateral weakness of the extremities142 (62.6\%), sudden trouble with walking or loss of balance were and 137 $(60.4 \%)$ were the most commonly identified warning signs, whereas $46(20.3 \%)$ of them had not mentioned any warning signs of stroke and only Less than half (42.7\%) of study respondents had adequate knowledge of stroke warning signs. This study finding was relatively consistent with studies conducted in Lebanon that show around a third (31.8\%) of the study participants could not recall any stroke symptom. ${ }^{31}$ Additionally, there was a relative similarity with a study conducted in Nigeria that shows study participants identified the weakness of 
Table 3 Warning Signs of Stroke Identified by Patients with Heart Disease Who Were on Follow-Up at TASH, $2020(n=227)$

\begin{tabular}{|c|c|c|c|}
\hline Variables & & Frequency & Percent \\
\hline $\begin{array}{l}\text { Sudden unilateral } \\
\text { numbness/weakness of } \\
\text { the face, arm, or leg }\end{array}$ & $\begin{array}{l}\text { Yes } \\
\text { No } \\
\text { I do not know }\end{array}$ & $\begin{array}{l}142 \\
39 \\
46\end{array}$ & $\begin{array}{l}62.6 \\
17.2 \\
20.3\end{array}$ \\
\hline $\begin{array}{l}\text { Sudden trouble with } \\
\text { walking, loss of balance }\end{array}$ & $\begin{array}{l}\text { Yes } \\
\text { No } \\
\text { I do not know }\end{array}$ & $\begin{array}{l}137 \\
49 \\
41\end{array}$ & $\begin{array}{l}60.4 \\
21.6 \\
18.1\end{array}$ \\
\hline $\begin{array}{l}\text { Sudden trouble with } \\
\text { speaking or } \\
\text { communication problem }\end{array}$ & $\begin{array}{l}\text { Yes } \\
\text { No } \\
\text { I do not know }\end{array}$ & $\begin{array}{l}115 \\
57 \\
55\end{array}$ & $\begin{array}{l}50.7 \\
25.1 \\
24.2\end{array}$ \\
\hline $\begin{array}{l}\text { Sudden severe headache } \\
\text { with no known causes }\end{array}$ & $\begin{array}{l}\text { Yes } \\
\text { No } \\
\text { I do not know }\end{array}$ & $\begin{array}{l}125 \\
49 \\
53\end{array}$ & $\begin{array}{l}55.1 \\
21.6 \\
23.3\end{array}$ \\
\hline $\begin{array}{l}\text { Sudden trouble with } \\
\text { seeing in one or both } \\
\text { eyes }\end{array}$ & $\begin{array}{l}\text { Yes } \\
\text { No } \\
\text { I do not know }\end{array}$ & $\begin{array}{l}93 \\
76 \\
58\end{array}$ & $\begin{array}{l}41.0 \\
33.5 \\
25.6\end{array}$ \\
\hline
\end{tabular}

part of body $52(36.1 \%)$ and $79(54.9 \%)$ of study participants had good symptom knowledge. ${ }^{27}$ The possible reason for this similarity might be due to identical study participants' selection method, sample size calculation and study design. However, a study conducted in Thailand revealed that 19 (13.6\%) of participants could not identify any warning signs and only $6(4.3 \%)$ of them identified sudden unilateral numbness of extremities, ${ }^{28}$ which shows lower than our study finding, that might occur due to researchers used an open-ended questionnaire to carry out the study. Furthermore, this study findings were higher than a study conducted in Ethiopia, which shows $217(77.3 \%)$ of participants did not identify any warning signs of a stroke, $2(0.7 \%)$ identified 3 warning signs and $(35.9 \%)$ of them recalled sudden weakness or paralysis on one side of the body. ${ }^{13}$ The inconsistencies might be due to health care information outcome in response time and that study was conducted at the peripheral region of the country that might result in healthcare information access gap.

In the multivariable logistic regression analysis, those who had higher education level was three times more likely to had adequate knowledge of risk factors (AOR 3.05; 95\% CI 1.62-5.74), the odds of having adequate knowledge in urban residence area was 2.07 times (AOR 2.07; 95\% CI 1.05-4.1) more likely than rural area residents. Furthermore, those who know somebody with stroke were 2.67 times (AOR 2.67; 95\% CI 1.29-5.55) more likely to have adequate knowledge of stroke risk factors. This study finding was similar to a study conducted in Nigeria that reveals higher educational level (OR $11.3,95 \%$ CI, 2.88-44.6, $\mathrm{P}<0.001$ ), are found to be significant predictors of good knowledge of stroke risk factors. ${ }^{27}$ Besides this study conducted in Central Pennsylvania shows that a high level of education increases odds of recognition of $>3$ correct stroke risk factors $(0.21 ; 95 \% \mathrm{CI}, 0.09-0.61)$ with additional Knowing anyone with stroke was associated with knowledge of stroke risk factor. ${ }^{30}$ Also, our study finding was consistent with a study conducted in Spain and Ethiopia that shows

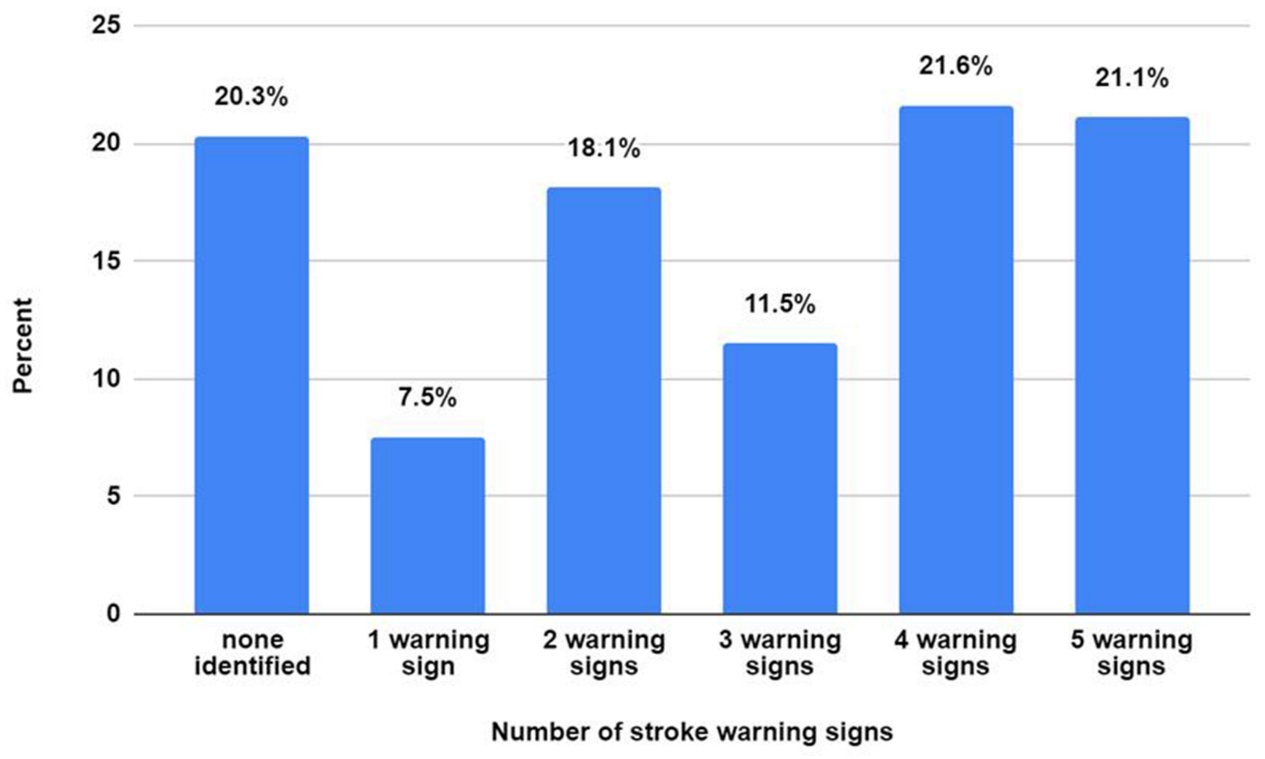

Figure 2 Number of warning signs of stroke identified by patients with heart disease who were on follow-up at TASH, 2020. 
Table 4 Binary Logistic Regression of Factors Associated with Knowledge of Stroke Risk Factors and Warning Signs Among Cardiac Patients Who Were on Follow-Up at TASH, 2020

\begin{tabular}{|c|c|c|c|c|c|}
\hline \multicolumn{2}{|l|}{ Variables } & \multicolumn{2}{|c|}{ Knowledge of Risk Factors } & \multicolumn{2}{|c|}{ Knowledge of Warning Signs } \\
\hline & & P-value & OR (95\% C.I) & P-value & OR (95\% C.I) \\
\hline Age & $\begin{array}{l}\geq 45 \\
<45\end{array}$ & 0.050 & $\begin{array}{l}2.03(1.00-4.12) \\
1\end{array}$ & 0.202 & $\mathrm{I} .69(0.76-3.78)$ \\
\hline Sex & $\begin{array}{l}\text { Male } \\
\text { Female }\end{array}$ & 0.887 & $\begin{array}{l}0.95(0.46-1.95) \\
1\end{array}$ & 0.458 & $\begin{array}{l}0.74(0.33-1.64) \\
1\end{array}$ \\
\hline Marital status & $\begin{array}{l}\text { Single } \\
\text { Married } \\
\text { Divorced } \\
\text { Widowed }\end{array}$ & $\begin{array}{l}0.059 \\
0.745 \\
0.513 \\
0.189\end{array}$ & $\begin{array}{l}1.32(0.25-7.02) \\
0.54(0.09-3.40) \\
3.78(0.52-27.56) \\
1\end{array}$ & $\begin{array}{l}0.265 \\
0.982 \\
0.901 \\
0.196\end{array}$ & $\begin{array}{l}1.02(0.16-6.34) \\
1.14(0.15-8.66) \\
4.12(0.48-35.13) \\
\text { I }\end{array}$ \\
\hline Occupation & $\begin{array}{l}\text { Merchant } \\
\text { Farmer } \\
\text { Government employee } \\
\text { House wife }\end{array}$ & $\begin{array}{l}0.154 \\
0.248 \\
0.055 \\
0.013\end{array}$ & $\begin{array}{l}2.19(0.58-8.22) \\
10.74) \\
5.23(1.41-19.39) \\
1\end{array}$ & $\begin{array}{l}0.158 \\
0.100 \\
0.141 \\
0.032 \\
0.606\end{array}$ & $\begin{array}{l}3.40(0.79-\mid 4.58) \\
2.8 I(0.7 I-\mid I .15) \\
5.17(I .16-23.15) \\
I .36(0.43-4.33)\end{array}$ \\
\hline Educational status & $\begin{array}{l}\text { Secondary school or above } \\
\text { Elementary school or less }\end{array}$ & 0.030 & $\begin{array}{l}2.28(1.08-4.82) \\
1\end{array}$ & 0.010 & $\begin{array}{l}3.04(1.31-7.08) \\
I\end{array}$ \\
\hline Residence area & $\begin{array}{l}\text { Urban } \\
\text { Rural }\end{array}$ & 0.076 & $\begin{array}{l}2.18(0.92-5.19) \\
1\end{array}$ & 0.372 & $\begin{array}{l}1.53(0.60-3.90) \\
\mathrm{I}\end{array}$ \\
\hline Monthly income & $\begin{array}{l}\geq 5000 \text { ETB } \\
<5000 \text { ETB }\end{array}$ & 0.437 & $\begin{array}{l}1.40(0.60-3.24) \\
\mathrm{I}\end{array}$ & $0.58 \mathrm{I}$ & $\begin{array}{l}\mathrm{I} .30(0.5 \mathrm{I}-3.32) \\
\mathrm{I}\end{array}$ \\
\hline Heard about a stroke before & $\begin{array}{l}\text { Yes } \\
\text { No }\end{array}$ & 0.037 & $\begin{array}{l}1.07(0.50-2.23) \\
\text { । }\end{array}$ & 0.024 & $\begin{array}{l}1.49(0.65-3.37) \\
\text { I }\end{array}$ \\
\hline Know somebody with stroke & $\begin{array}{l}\text { Yes } \\
\text { No }\end{array}$ & 0.010 & $\begin{array}{l}2.83(1.28-6.20) \\
1\end{array}$ & 0.000 & II $.02(4.42-27.46)$ \\
\hline
\end{tabular}

having a secondary/higher level of education were the predictors of good knowledge of risk factors (OR 3.19, 95\% CI $1.70-5.74 ; \mathrm{p}=0.003)$ and $(\mathrm{AOR}=7.128$, CI 95\% 2.29822.108) respectively. ${ }^{13,32}$ This similarity might be due to more literate can look up about their health from different sources. Contrasted to this study conducted in Turkey shows that there is no relationship between stroke knowledge and educational level. ${ }^{29}$ The possible justification for this inconsistency was due to the study participant's difference among the studies.

Our study shows that age of patients, marital status, and sex of participants had no significant association ( $p$-value $>0.05$ ) with knowledge of stroke risk factors and warning signs which is a contrast to studies conducted in Ethiopia that shows respondents aged $<45$ are more likely to have good knowledge of stroke risk factors and warning signs ( $\mathrm{AOR}=2.56, \mathrm{CI} 95 \%$ $1.115-6.015)$ than respondents who aged 45 years. ${ }^{13}$ This study also contrasts with a study conducted in Korea that reveals a significant association between gender and age knowledge of stroke with good knowledge of stroke risk factors. ${ }^{33}$ The possible reason might be due to sociodemographic differences among regions. However, our study findings were similar to studies conducted in Turkey which show there is no relationship of stroke knowledge with age $\left(p>0.05\right.$ each).$^{29}$ Furthermore, a study conducted in Nigeria shows sex and marital statuses of study participants were not predictors of knowledge of stroke risk factors and warning signs. ${ }^{27}$

\section{Limitation and Strength of the Study}

The strength of this study was its attempts to generalize knowledge of stroke risk factors and warning signs with an appropriate selection of study area in which different 
Table 5 Multivariate Logistic Regression of Factors Associated with Knowledge of Stroke Risk Factors and Warning Signs Among Cardiac Patients Who Were on Follow-Up at TASH, 2020

\begin{tabular}{|c|c|c|c|c|c|c|c|}
\hline \multicolumn{2}{|l|}{ Variables } & \multicolumn{3}{|c|}{ Knowledge of Risk Factors } & \multicolumn{3}{|c|}{ Knowledge of Warning Signs } \\
\hline & & \multirow{2}{*}{$\begin{array}{l}\text { AOR }(95 \% \mathrm{Cl}) \\
1.8(0.95-3.47)\end{array}$} & \multirow{2}{*}{$\begin{array}{l}\text { COR }(95 \% \mathrm{CI}) \\
1.63(0.96-2.76) \\
1.00\end{array}$} & \multirow{2}{*}{$\begin{array}{l}\text { P-value } \\
0.069\end{array}$} & \multirow{2}{*}{$\begin{array}{l}\text { AOR }(95 \% \mathrm{Cl}) \\
\mathrm{I} .66(0.8 \mathrm{I}-3.4 \mathrm{I})\end{array}$} & \multirow{2}{*}{$\begin{array}{l}\text { COR 95\% CI } \\
1.55(0.91-2.64) \\
1.00\end{array}$} & \multirow{2}{*}{$\begin{array}{l}\text { P-value } \\
0.107\end{array}$} \\
\hline Age & $\begin{array}{l}\geq 45 \\
<45\end{array}$ & & & & & & \\
\hline Sex & $\begin{array}{l}\text { Male } \\
\text { Female }\end{array}$ & & $\begin{array}{l}0.86(0.58-1.29) \\
1.00\end{array}$ & 0.898 & & $\begin{array}{l}0.82(0.48-1.40) \\
1.00\end{array}$ & 0.481 \\
\hline Marital status & $\begin{array}{l}\text { Married } \\
\text { Single } \\
\text { Divorced } \\
\text { Widowed }\end{array}$ & & $\begin{array}{l}2.25(0.57-8.83) \\
1.92(0.446-8.25) \\
5.87(1.07-32.02) \\
1.00\end{array}$ & 0.183 & & $\begin{array}{l}1.17(0.33-4.17) \\
1.52(0.39-5.97) \\
2.92(0.59-14.33) \\
1.00\end{array}$ & 0.349 \\
\hline Educational status & $\begin{array}{l}\text { Elementary school or less } \\
\text { Secondary school or } \\
\text { above }\end{array}$ & $\begin{array}{l}1.00 \\
3.05(1.62-5.74)\end{array}$ & $\begin{array}{l}1.00 \\
4.27(2.45-7.45)\end{array}$ & $0.005^{*}$ & $\begin{array}{l}1.00 \\
4.29(2.25-8.19)\end{array}$ & $\begin{array}{l}1.00 \\
4.91(2.7-8.68)\end{array}$ & $0.011^{*}$ \\
\hline Occupation & $\begin{array}{l}\text { Farmer } \\
\text { Merchant } \\
\text { Govt. employee } \\
\text { Housewife }\end{array}$ & $\begin{array}{l}2.61(0.93-7.30) \\
4.28(1.32-13.89) \\
2.08(0.60-7.25)\end{array}$ & $\begin{array}{l}1.00 \\
4.36(1.58-12.04) \\
8.33(2.76-25.16) \\
1.07(0.41-2.81)\end{array}$ & 0.000 & $\begin{array}{l}1.00 \\
3.07(0.97-9.68) \\
3.78(1.10-12.97) \\
1.80(0.58-5.56)\end{array}$ & $\begin{array}{l}1.00 \\
3.77(1.39-10.21) \\
6.13\left(2.11 \_17.82\right) \\
0.84(0.323-2.19)\end{array}$ & 0.0001 \\
\hline Residence area & $\begin{array}{l}\text { Urban } \\
\text { Rural }\end{array}$ & $\begin{array}{l}2.07(1.05-4.1) \\
1.00\end{array}$ & $\begin{array}{l}3.18(1.74-5.82) \\
1.00\end{array}$ & $0.036^{*}$ & & $\begin{array}{l}2.41(1.33-4.38) \\
1.00\end{array}$ & 0.004 \\
\hline Hearing about stroke & $\begin{array}{l}\text { Yes } \\
\text { No }\end{array}$ & $2.67(1.24-5.76)$ & $\begin{array}{l}2.74(1.59-4.69) \\
1.00\end{array}$ & 0.000 & $1.73(0.80-3.78)$ & $\begin{array}{l}5.16(2.89-9.18) \\
1.00\end{array}$ & 0.017 \\
\hline $\begin{array}{l}\text { Know somebody with } \\
\text { stroke }\end{array}$ & $\begin{array}{l}\text { Yes } \\
\text { No }\end{array}$ & $2.67(1.29-5.55)$ & $\begin{array}{l}2.82(1.43-5.54) \\
1.00\end{array}$ & $0.008 *$ & II.II(5.24-23.59) & $\begin{array}{l}12.35(6.03-25.28) \\
1.00\end{array}$ & $0.000^{*}$ \\
\hline
\end{tabular}

Note: *P-value $<0.05$ in multivariate logistic regression.

Abbreviations: AOR, adjusted odds ratio; COR, crude odds ratio.

regions of the country's patients were referred to it. Additionally, data quality control was highly practiced throughout the data collection as well as questionnaires were translated to two languages to interview participants.

Some limitations of the study were: firstly, since this study was limited by a single centered facility-based study selection bias can be an issue. Secondly, the study was limited to patients with heart disease only so it could not address the knowledge of stroke risk factors and warning signs in large populations in an ultimate way.

\section{Conclusion}

The study shows that participants had inadequate knowledge of stroke risk factors, with around one-fifth of the patients unable to identify any risk factors of stroke. More than half of patients had inadequate knowledge of warning signs of stroke and around one-fifth did not know any warning signs of a stroke. Educational status, residence area, and knowing somebody with stroke had a statistically significant association ( $p$ value $<0.05$ ) with adequate knowledge of stroke risk factors and warning signs, while gender, sex, and marital status did not have a significant association with knowledge of risk factor and warning signs of a stroke.

\section{Acknowledgments}

Our special thanks will go to Jimma University and Addis Ababa University for their financial and technical support.

\section{Disclosure}

We disclose that this manuscript was based on Abdata Workina's Master's thesis. The authors report no conflicts of interest in this research work.

\section{References}

1. McCoy E, Langdorf M, Lotfipour S. American Heart Association/ American Stroke Association deletes sections from 2018 stroke guidelines. West J Emerg Med. 2018;19(6):947-951. doi:10.5811/ westjem.2018.9.39659

2. Hickey A, Mellon L, Williams D, Shelley E, Conroy RM. Impact of the face, arm, speech and time (FAST) campaign on population knowledge of stroke risk factors, warning signs and emergency response. Eur Stroke J. 2018;3(2):117-125. doi:10.1177/2396987317753453 
3. Johnson W, Onuma O, Owolabi M, Sachdev S. Stroke: a global response is needed. Bull World Health Organ. 2016;94(9):634 634A. doi:10.2471/BLT.16.181636

4. Fisher M, Iadecola C, Sacco R. Introduction to the stroke compendium. Circ Res. 2017;120(3):437-438. doi:10.1161/ CIRCRESAHA.116.310453

5. Zeina H, Mona O, Reem H. Primary care physicians' awareness and perceptions on adherence to primary cardiovascular disease prevention guidelines in Lebanon. 2021. Available from: https://journals.sagepub. com/doi/full/10.1177/1742395320983879. Accessed January 27, 2021.

6. Jauch EC, Saver JL, Adams HP, et al. A guideline for healthcare professionals from the American heart association/American stroke association. stroke. 2013:870-894. doi:10.1161/STR.0b013e3 $18284056 \mathrm{a}$

7. Valery LF, Norrving B, George MG, Foltz JL, Roth G. Prevention of stroke: a strategic global imperative. Nat Rev Neurol. 2016;12 (9):501-512. doi:10.1038/nrneurol.2016.107

8. Lindsay M, Furie K, Norrving B, Donnan G, Langhorne P, Davis S. Global Stroke Guidelines and Action Plan All in One. World stroke organization; 2016. Available from: www.world-stroke.org. Accessed January 27, 2021.

9. Hickey A, Holly D, McGee H, Conroy R, Shelley E. Knowledge of stroke risk factors and warning signs in ireland: development and application of the Stroke Awareness Questionnaire (SAQ). Int $J$ Stroke. 2012;7(4):298-306. doi:10.1111/j.1747-4949.201 1.00698.x

10. Workina A, Kebede S, Fekladu C, Wubetie A. Knowledge of risk factors and warning signs of stroke among patients with heart disease at tikur anbessa specialized hospital [internet]. 2020. Available from: http://etd.aau.edu.et/handle/123456789/21936. Accessed January 27, 2021.

11. Johnson S, Fong $\mathrm{K}$, Hills $\mathrm{N}$, et al. Prioritizing interventions to improve rates of thrombolysis for ischemic stroke. Neurology. 2015;64:654-659.

12. Dar NZ, Khan SA, Ahmad A, Maqsood S. Awareness of stroke and health-seeking practices among hypertensive patients in a tertiary care hospital: a Cross-sectional Survey. Cureus. 2019;11(5):e4774. doi: $10.7759 /$ cureus.4774

13. Abate AT, Bayu N, Mariam TG. Hypertensive patients' knowledge of risk factors and warning signs of stroke at Felege Hiwot Referral Hospital, Northwest Ethiopia. Neurol Res Int. 2019;7. doi:10.1155/ 2019/8570428

14. Meschia JF, Bushnell C, Boden-Albala B, et al. Guidelines for the primary prevention of stroke. Stroke J Cerebral Circ. 2014;45 (12):3754-3832. doi:10.1161/STR.0000000000000046

15. Donkor ES. Stroke in the $21 \mathrm{~s} \mathrm{t}$ century: a snapshot of the burden, epidemiology, and quality of life. Stroke Res Treat. 2018;2018:1-10. doi:10.1155/2018/3238165

16. Fekadu G, Wakassa H, Tekle F. Stroke event factors among adult patients admitted to stroke unit of Jimma University Medical Center: prospective Observational Study. Stroke Res Treat. 2019;2019:1-8. doi:10.1155/2019/4650104

17. Shiferaw F, Letebo M, Misganaw A, et al. Non-communicable diseases in Ethiopia: disease burden, gaps in health care delivery and strategic directions. Ethiop J Health Dev. 2018;32(3):9-11.

18. Sultan M, Debebe F, Azazh A, Hassen GW. Epidemiology of stroke patients in Tikur Anbessa Specialized Hospital: emphasizing clinical characteristics of hemorrhagic stroke patients. Ethiop J Health Dev. 2017;31(1):13-17.
19. Zewdie A, Debebe F, Kebede S, et al. Prospective assessment of patients with stroke in Tikur Anbessa Specialized Hospital, Addis Ababa, Ethiopia. Afr J Emerg Med. 2018;8:21-24. doi:10.1016/j. afjem.2017.11.001

20. Benjamin EJ, Blaha MJ, Chiuve SE, et al. Heart disease and stroke statistics - 2017 update. Circulation. 2017;135(10):e146-e603.

21. Tolla MT, Norheim OF, Memirie ST, et al. Prevention and treatment of cardiovascular disease in Ethiopia. Cost Eff Resour Alloc. 2016;14 (1):10. doi:10.1186/s12962-016-0059-y

22. Temesgen TG, Teshome B, Njogu P. Treatment outcomes and associated factors among hospitalized stroke patients at Shashemene Referral Hospital, Ethiopia. Stroke Res Treat. 2018;2018:1-5. doi: $10.1155 / 2018 / 8079578$

23. Howard G, Schwamm LH, Donnelly JP, et al. Participation in get with the guidelines-stroke and its association with quality of care for stroke. JAMA Neurol. 2018;75(11):1331-1337. doi:10.1001/ jamaneurol.2018.2101

24. Johnson CO, Nguyen M, Roth GA, et al. Global, regional, and national burden of stroke, 1990-2016: a systematic analysis for the Global Burden of Disease Study 2016. Lancet Neurol. 2019;18 (5):439-458. doi:10.1016/S1474-4422(19)30034-1

25. Stroebele N, Müller-Riemenschneider F, Nolte $\mathrm{CH}$, MüllerNordhorn J, Bockelbrink A, Willich SN. Knowledge of risk factors, and warning signs of stroke: a systematic review from a gender perspective. Int $J$ Stroke. 2011;6(1):60-66. doi:10.1111/j.17474949.2010.00540.x

26. Tikur Anbessa Specialized Hospital. College of health sciences [internet]. [cited November 18, 2019]. Available from: http://www. aau.edu.et/chs/tikur-anbessa-specialized-hospital/. Accessed January 27,2021

27. Odiase F. Awareness of stroke risk factors and warning symptoms amongst hypertensive patients in Benin City. Ann Med Health Sci Res. 2018;8(1):5.

28. Saengsuwan J, Suangpho P, Tiamkao S. Knowledge of stroke risk factors and warning signs in patients with recurrent stroke or recurrent transient ischaemic attack in Thailand. Neurol Res Int. 2017;2017:8215726. doi:10.1155/2017/8215726

29. Yesilbalkan OU, Karadakovan A, Dogru BV, Akman P, Ozel E, Bozturk Y. Awareness of risk factors and warning signs of stroke among caregivers of patients with and not with stroke: results from questionnaire. J Pak Med Assoc. 2019;69(8):1114-1118.

30. Sadighi A, Groody A, Wasko L, Hornak J, Zand R. Recognition of stroke warning signs and risk factors among rural population in Central Pennsylvania. J Vasc Interv Neurol. 2018;10(2):4-10.

31. Mohammad K, Nathalie L. Knowledge of stroke warning signs, risk factors, and response to stroke among Lebanese older adults in Beirut. J Stroke Cerebrovasc Dis. 2020;29(5):1-9.

32. Soto-Cámara R, González-Bernal JJ, González-Santos J, AguilarParra JM, Trigueros R, López-Liria R. Knowledge on signs and risk factors in stroke patients. J Clin Med. 2020;9(8):2557. doi:10.3390/jcm9082557

33. Kim EM, Hwang SY, Kim AL. Knowledge of stroke and heart attack symptoms and risk factors among rural elderly people: a questionnaire survey. Korean Circ J. 2011;41(5):259. doi:10.4070/ kcj.2011.41.5.259 


\section{Publish your work in this journal}

The Open Access Emergency Medicine is an international, peerreviewed, open access journal publishing original research, reports, editorials, reviews and commentaries on all aspects of emergency medicine. The manuscript management system is completely online and includes a very quick and fair peer-review system, which is all easy to use. Visit http://www.dovepress.com/testimonials.php to read real quotes from published authors.

Submit your manuscript here: https://www.dovepress.com/open-access-emergency-medicine-journal 